\title{
Construction and Monitoring of Cement/Bentonite Cutoff Walls: Case Study of Karkheh Dam, Iran
}

https://doi.org/10.2478/sgem-2019-0019

received November 19, 2018; accepted June 14, 2019.

\begin{abstract}
Water seepage is one of the most important features of embankment dams. To prevent and reduce seepage, it is necessary to seal the dam. Plastic concrete cutoff walls are one of the most efficient methods in waterproofing the foundation of embankment dams on permeable alluvial substrates. Sufficient resistance to loads, low permeability to maintain dam sealing, high ductility compatible with the foundation and deformation under load without cracking are the main requirements in plastic concrete cutoff walls. In this paper, the construction and implementation of the cutoff wall of Karkheh Dam, which is one the world's largest water sealing projects, was studied. In addition, a numerical model using Seep-3D software was developed to evaluate the efficiency of the cut-off wall to decrease the seepage over the dam's foundation. The numerical results validated by instrumentation statistics resulted from 17-years dam operation. According to the results, after the drainage of the reservoir, the cutoff wall optimally reduced the hydraulic gradient by 0.08 from 2.35 and the water leakage by $3.1 \mathrm{~m} / \mathrm{s}$ from $18.3 \mathrm{~m} / \mathrm{s}$.
\end{abstract}

Keywords: Cutoff wall; permeation; Karkheh Dam; sealing; hydrofraise.

\section{Introduction}

Karkheh Dam located in Khuzestan province in Iran and $25 \mathrm{~km}$ northwest of the city of Andimeshk became operational in 2001 to control the floods of Karkheh River

\footnotetext{
*Corresponding author: Iman Faridmehr, South Ural State University, 454080 Chelyabinsk, Lenin Prospect 76, Russian Federation, E-mail: s.k.k-co@live.com

Mohammad Reza YazdaniPour, Mohammad Javadi Jokar, Production Operation Company of Karkheh Dam Hydropower Plant, Andimeshk, Khuzestan, Iran
}

Togay Ozbakkaloglu, School of Engineering and Technology, University of Hertfordshire, UK along with the development of water and soil resources of the catchment area. Karkheh Dam, with a reservoir volume of 7.4 billion cubic meters in flood condition and 5.6 billion cubic meters under normal levels, is the largest Iranian dam in water storage history (Fig. 1).

The Karkheh Dam Project had the largest cutoff wall in the world at the time. The cutoff wall of the Karkheh Dam was made of plastic concrete that met the required strength and ductility criteria. The final wall surface was about 150,000 cubic meters and was built up to a depth of 80 meters and an average depth of approximately 50 meters and a foundation length of 3030 meters under the axis of dam. The thickness of the wall in most parts was 1 $\mathrm{m}$ and in the left wing area of the dam was $0.8 \mathrm{~m}$.

Since the foundation of the Karkheh Dam is composed of different layers of weak aggregates,

the dam is placed on poorly/fairly permeable conglomerate beds, which are moderately cemented, different options were investigated regarding the sealing of its foundation in the preliminary study phase. At the beginning of the design of the Karkheh Dam and Hydropower Plant Project, curtain injection was suggested to control the foundation seepage below the dam. ${ }^{[1]}$ However, after thorough on-site injection tests

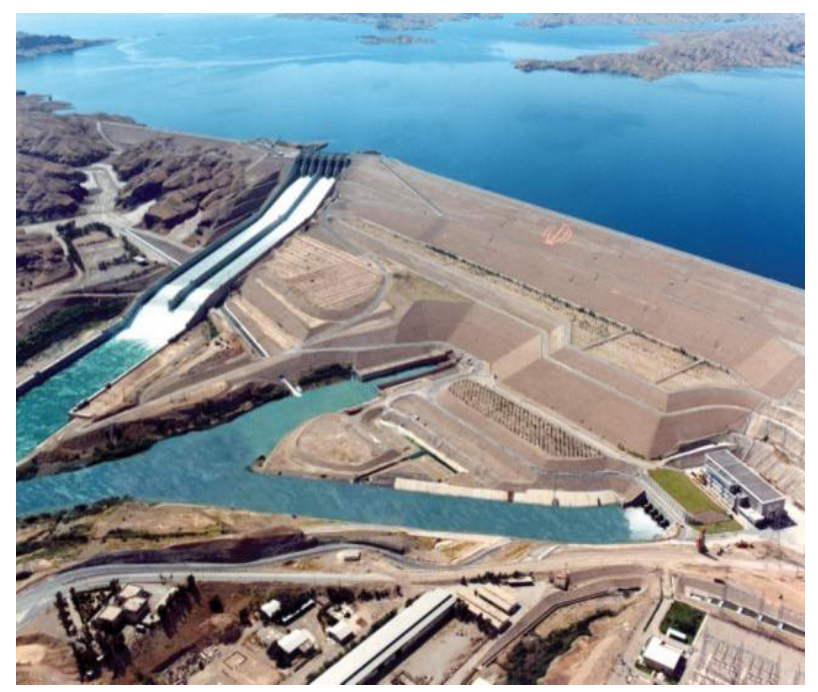

Figure 1: Karkheh Dam, Iran. 


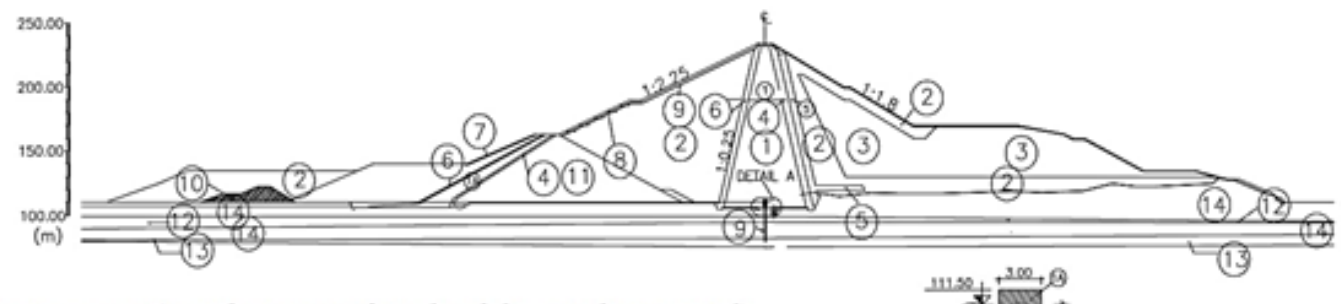

1. Impervious core (mudstone mixed with sandy gravel)

2. Sandy gravel

3. Conglomerate or sandy gravel

4. Sand filter

5. Gravel filter and drain

6. Sand-gravel filter

7. U/S slope protection using limestone riprap

8. U/S slope protection using soil cement

9. Plastic concrete cut off wall

\section{Pre-coffer dam}

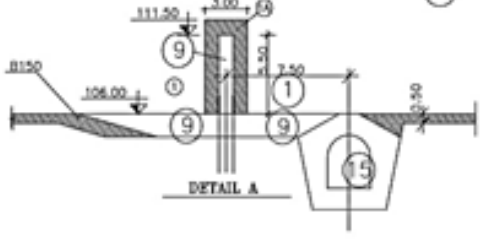

13. Mudstone no. (-2)

14. Conglomerate

15. Inspection gallery

11. Main cofferdam

1A. Impervious core (mudstone)

12. Mudstone no. (-1)

Figure 2: Cross-section and connection details between the cutoff wall and dam foundation.

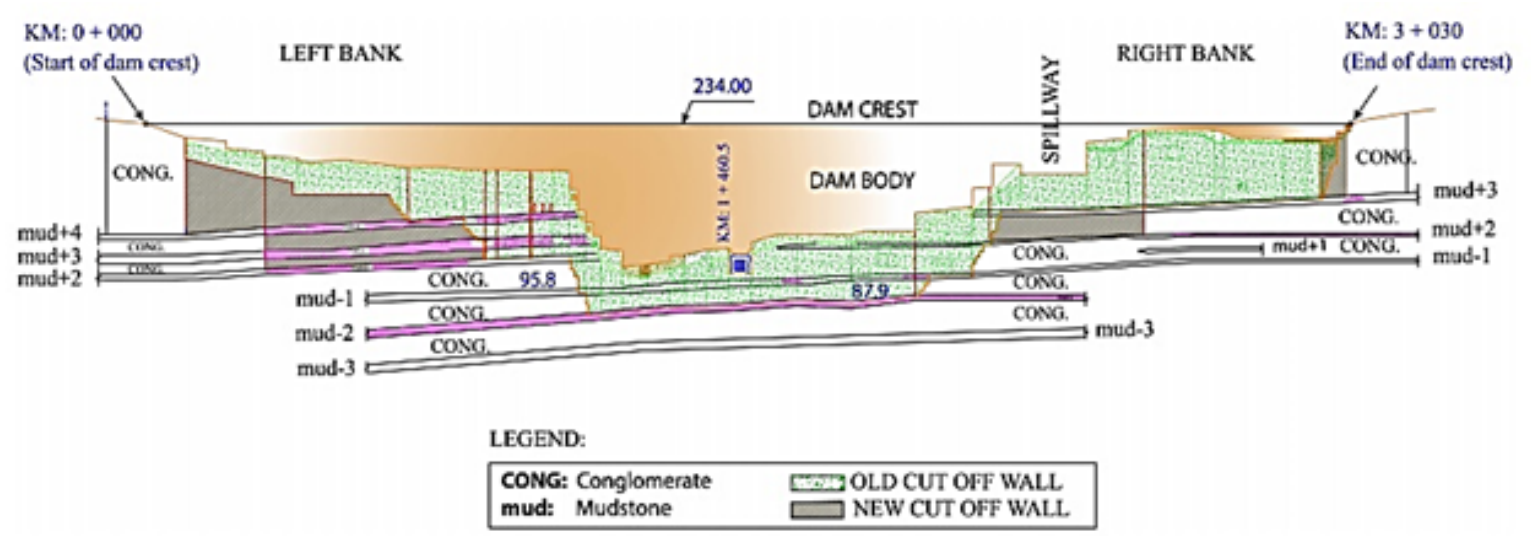

Figure 3: Longitudinal section of Karkheh Dam showing dam geological layers.

and extensive financial studies, implementation of a cutoff wall was considered as another option for sealing of the dam foundation. The reason for the selection of this approach was the slow implementation of the project using the "curtain injection" method, in addition to the economic and technical problems. Karkheh's conglomerate foundation consists of water-resistant horizontal mudstone layers each having a thickness of 3 to $9 \mathrm{~m}$. The permeability of these layers, which are bedded almost horizontally, is in the range of $10^{-7}-10^{-10} \mathrm{~m} / \mathrm{s}$. Geotechnical investigations revealed that these layers are continuous enough to provide different strata for each conglomerate layer confined by the mudstone layers.
Fig. 2 and 3 show the cross and longitudinal sections of Karkheh Dam respectively.

Restoration of the reservoir in 2001 and following attainment of the reservoir level of 210.5 masl, considering the normal water level (220 masl), was related to extreme seepage over the foundation and abutments along with unacceptable hydraulic gradient (0.2). Accordingly, the extending of the cut-off wall system was taken into account through providing four new sections at a different location as shown in Fig 4. The main objective of constructing the complementary cut-off wall was to decline the hydraulic gradient of seepage. The construction of complementary cut-off walls sections was a difficult engineering task as 


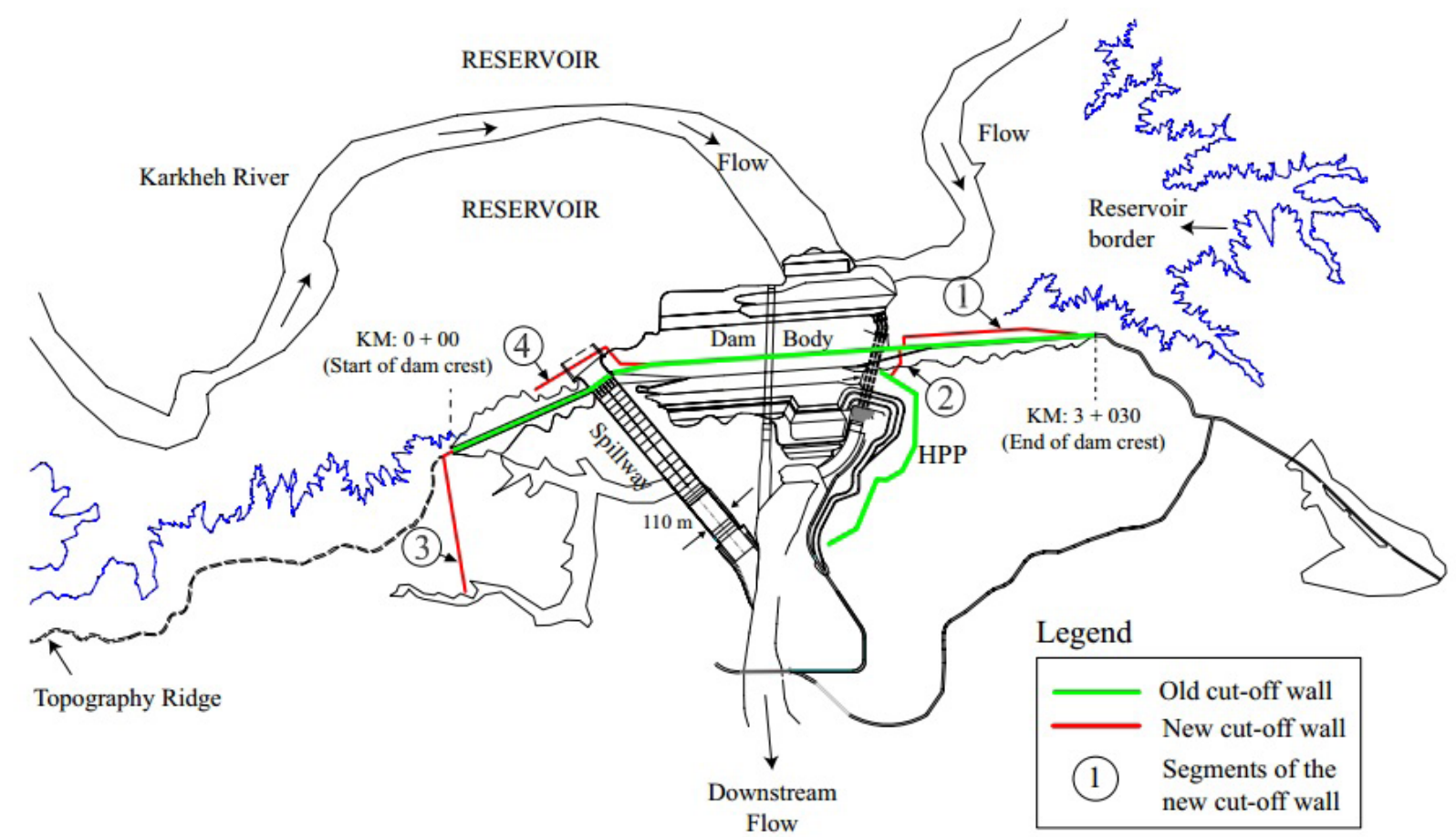

HPP stands for Hydro Power Plant

Figure 4: Plan of the Karkheh dam showing old and complementary cutoff wall.

these were supposed to constructed through the dam body and the excavation was extended to the depth up to $115 \mathrm{~m}$.

In this research, at first, the design criteria and construction methods of cutoff walls were investigated. After that, to investigate the Karkheh Dam's cutoff wall performance, a numerical model using Seep-3D software was developed. In this model, the effectiveness of the cut-off wall to decrease pore-water pressure in Dam's foundation under permanent and transient flow was investigated. Finally, the numerical results were validated by instrumentation statistic resulted over 17-years dam's operation.

\section{Literature Review}

One of the biggest dangers of dams after drainage is the leakage from the dam's substructure, which results in an increased hydraulic gradient of the seepage stream compared to the critical hydraulic gradient and consequently, increased likelihood of dangerous phenomena such as piping. ${ }^{[2]}$ Considering the importance of seepage risks, foundation sealing is of great importance. Thereare different methods for sealing the damfoundation, which can be classified into two major categories: i) Grout Curtains and ii) Cutoff Walls that are chosen according to the geological texture. The general concept of cutoff walls includes replacement of inappropriate and highly permeable materials by high-quality materials that meet the design criteria. $^{[3]}$ The construction of cutoff walls could be described in two general steps: i) removal of inappropriate materials to reach an impermeable layer and ii) placement of selected aggregates or concrete. The cutoff wall under the dam foundation is locked into the clay core from the top. ${ }^{[4]}$ The wall is made of a special concrete called "plastic concrete", which is mechanically compatible with the dam's structure. ${ }^{[5,6]}$ The cutoff wall materials must be capable of resisting the deformations imposed by dam settlement and the wall's weight itself along with horizontal and vertical deformations due to horizontal loadings like earthquake loads and periodic loads due to the operation of dam reservoir. ${ }^{[7,8]}$

Construction of the first cutoff walls was conducted through Tangent Piles, Sheet Piles and T-shaped Piles. ${ }^{[9]}$ Yet, new construction methods of underground walls in unstable soils were introduced in the 1940s in Italy and spread throughout the world. ${ }^{[10]}$ The Slurry Trench Method of excavation ${ }^{[11,12]}$ was first proposed in the United States more than 70 years ago, and consequently, a cutoff wall was constructed by Slurry Trench Method in 1948 in the Iceland Terminal of California. ${ }^{[13]}$ The wall had a depth of 15 meters. After 30 years of using Continuous Flight 
Augering (CFA), also known as auger cast piling, walls with continuously excavated piles were made. The first deeply constructed cutoff wall using the above technology was built with Secant Piles. ${ }^{[14,}{ }^{15]}$ The combination of this method with previous methods resulted in the introduction of Stringer-Panel Method.

Several researchers investigated the cutoff wall performance in large dams. Pakbaz et al. investigate the Karkheh Dam's cut-off wall performance by using SEEP 3-D computer code and validation by actual seepage measurements. ${ }^{[16]}$ They concluded that seepage was significantly decreased and the integrity of the cut-off wall itself also warranted. Heidarzadeh et al. ${ }^{[17]}$ investigated several technical challenges during the Karkheh Dam's cut-off wall constructing, among which were: the connection between the new and old walls; trenching and placing of the plastic concrete wall through different dam body zones; and slurry loss during trenching through the dam body zones. The results of this study indicated that the cut-off wall helped to decrease both total seepage and the hydraulic gradient; for instance, total seepage was cut to $25 \%$ and the hydraulic gradient was reduced from 0.2 to 0.095. Lifeng Wen et al. investigated the behavior of cut-off walls on the basis of statistical analysis. ${ }^{[18]}$ In this study, detailed statistical analyses of horizontal displacement, crest settlement, cracking behavior and stress of the walls were performed based on the case histories. The findings and results of this study provide significant insight into concrete cut-off wall behavior and provide a valuable reference for future wall design and construction. Plastic concrete cut-off walls as the water sealing element of dam foundations have also been the subject of several studies. Xiong et al. ${ }^{[19]}$ performed stress deformation analysis for plastic concrete walls. Hinchberger et al. ${ }^{[20]}$ investigated the mechanical and hydraulic properties of plastic concrete.

\section{Design Criteria and Construction Methods of Karkheh Dam Cutoff Wall}

The cutoff wall was designed in conformity with low permeability criteria throughout the central axis below the core of the dam. ${ }^{[21]}$ In the middle parts of the dam, where the body height and hydrostatic load of the water are higher, the wall extends into one of the relatively thick non-impermeable layers of lichens below the dam and connects to lichen layers with higher levels with lower penetration depth. Expansion, thickness and physical properties of the rock masses that form the Karkheh Reservoir Dam site have a wide range of variations. The wall must be able to withstand the deformations and changes imposed by applied forces like settlement of the dam structure during and after construction, the forces resulting from the first drainage and the various conditions of the dam foundation, without cracking during the implementation and operation of the dam.

Due to the unique heterogeneous position of the dam foundation, the cutoff wall in Karkheh Dam was designed with plastic concrete, which was the common concrete mix proportion and bentonite aggregates (CemanBentonite Sherry Trenches Cut-Off Walls) and sometimes clay with a 28-day compressive strength of $2.94 \mathrm{MPa}$ and a permeability coefficient lower than $10 \sim 7 \mathrm{~cm} / \mathrm{sec}$. Also, in order to consider construction requirements, a desired slump of 16 to $22 \mathrm{~cm}$ for plastic concrete was chosen and the plastic concrete temperature during concrete pouring was less than 30 degrees Celsius. In different places of the dam, the depth of the wall was determined according to permeation analysis, executive facilities and economic studies. The thickness and penetration of the wall into the clay core were determined according to the following criteria:

1. Allowable hydraulic gradient

2. Permissible hydraulic fracture pressure

3. Allowable stresses and strains under different loading conditions

4. The minimum overlap between adjacent panels due to drilling deflection from the vertical axis at high depth.

In this type of wall, firstly, the trenches of the cutoff wall are drilled by drilling mud in the form of primary and secondary panels, and then, the drilled trench is filled with high performance, high workability plastic concrete using a Tremie pipe as shown in Fig 5.

For drilling purposes, the BC30-BS110-HDS (shortly BC30) drilling machine, made by Bauer Company in Germany, was used in the Karkheh Dam project. This machine is capable of drilling rectangular trenches of 0.82 m length, 64, 80, 100 and $120 \mathrm{~cm}$ thick with a maximum depth of $80 \mathrm{~m}$, with variations of up to 100 meters and eventually digging the excavated material out of the ground. In the vicinity of any hydrofraise, a collection of Desander and pools or liquid storage tanks, as well as new drilling mud production equipment is used. Desanders are composed of centrifugal vibrating screens, which separate the drilling mud from excavated gravel, sand and silt. This complex is connected to storage ponds and 

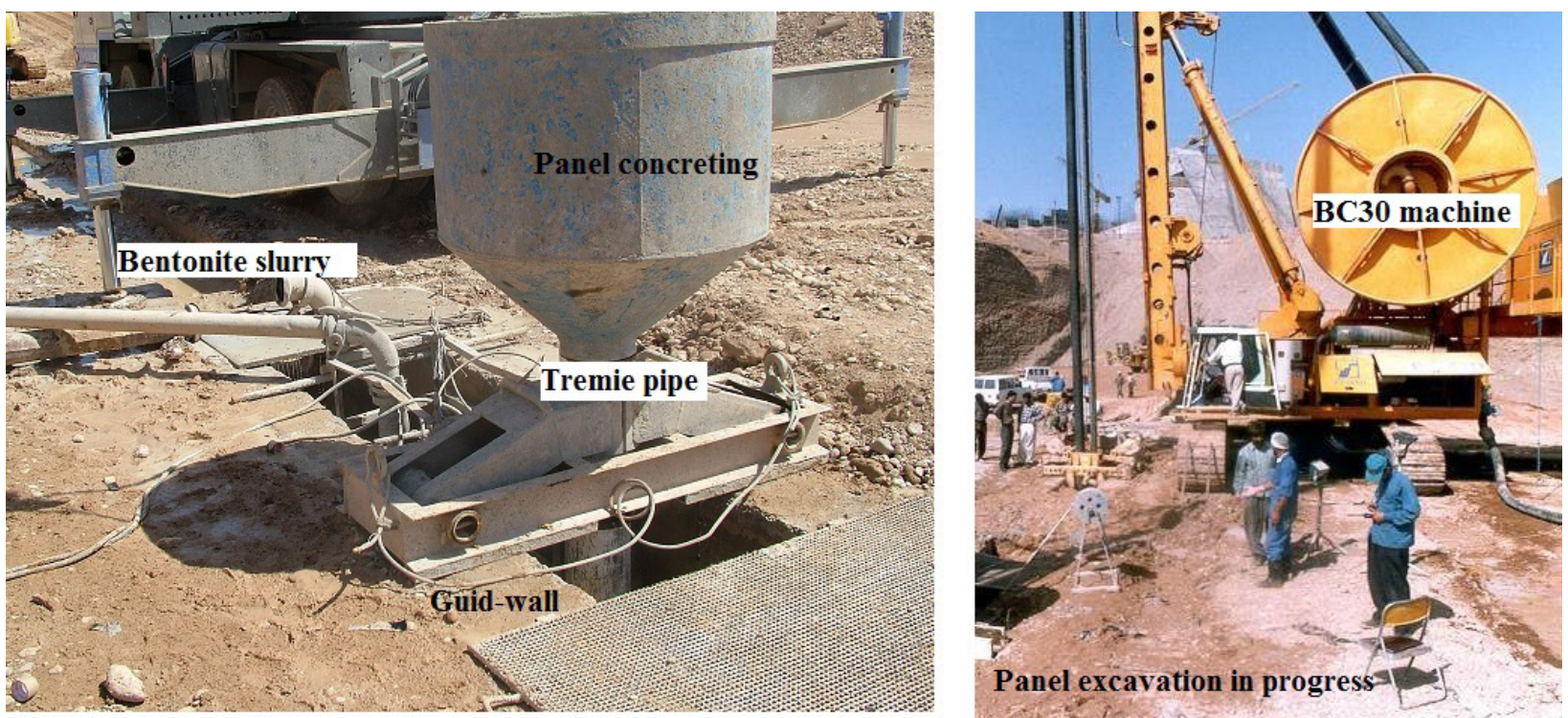

Figure 5: Construction of the cut-off wall.

hydrofraise through a network of pipes. The guide wall is a concrete wall used to guide and control the cutter of BC30 machine during excavation and prevent deviations in the initial depth of the panel. The guide wall is made of two parallel concrete beams constructed alongside the wall as a guide for excavation devices. The distance between these two parallel concrete beams is equal to the thickness of the cutoff wall plus $5 \mathrm{~cm}$ with equal distance from the cutoff wall axis (Fig 6). Concreting the panels is conducted by Tremie pipe, which prevents segregation of aggregates during the pouring process from a distance.

In general, the execution of the Karkheh cutoff wall included the following steps:

1. Core excavation

2. Embankment of clay core and filters and other areas of the body up to 2 meters above the upper elevations of the cutoff wall along with the construction of the central part of the core with connecting clay with a width of 3 meters

3. Construction of work platform with fine and coarse aggregates with required width and thickness, for installation of the drilling device, along with the construction of guide walls and finally the installation of the drilling device

4. Construction of the cutoff wall (excavation and concreting)

5. Removal of the work platform and guide walls in addition to removal of $0.2 \mathrm{~m}$ from the top of the clay core and $0.7 \mathrm{~m}$ from the top of the cutoff wall

6. Continued embankment of clay core, filters and other areas of the body

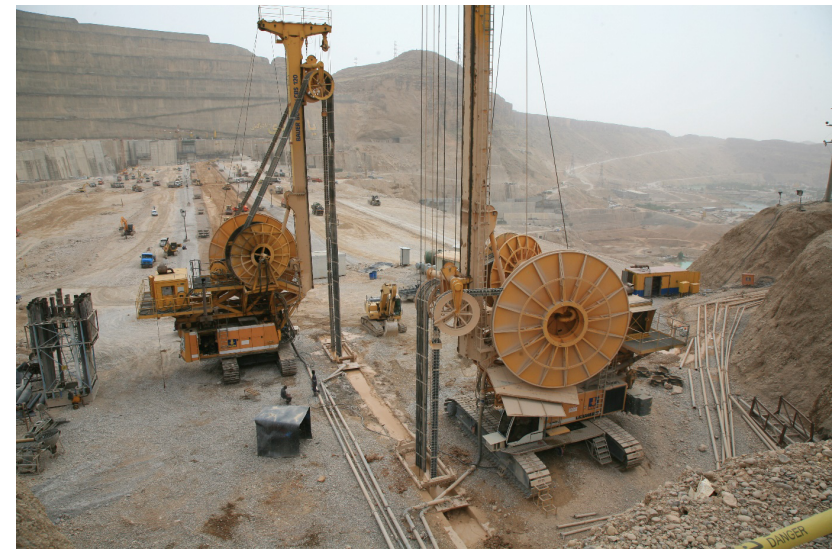

Figure 6: Excavation with $\mathrm{BC} 30$ machine alongside the guide wall.

\section{Materials Used in Cutoff walls}

\subsection{Drilling mud (Drilling fluid)}

The drilling mud used in the cut-off wall of Karkheh Dam was bentonite slurry, which was used to facilitate the excavation process. Cleaning the well from the drilling rigs, preventing the breakdown of the wall, cooling the digger and lubricating the cutter rotation is among the functions of the drilling mud. In the design process of Karkheh Dam, the following standards were considered for the characteristics of fresh mud, Table 1. 
Table 1: Drilling mud properties of the cutoff wall of Karkheh Dam

\begin{tabular}{llllll}
\hline & $\begin{array}{l}\text { Bentonite Cake } \\
(\mathrm{mm})\end{array}$ & $\begin{array}{l}\text { Gel Resistance after } 10 \\
\text { Minutes }\left(\mathbf{g} / \mathbf{c m}^{3}\right)\end{array}$ & $\begin{array}{l}\text { Filtration Losses } \\
\left(\mathbf{c m}^{3}\right)\end{array}$ & $\begin{array}{l}\text { Density } \\
\left(\mathbf{g} / \mathbf{c m}^{3}\right)\end{array}$ & $\begin{array}{l}\text { Marsh Funnel } \\
\text { Viscosity }(\mathbf{s})\end{array}$ \\
\hline $7 \sim 10$ & $<3$ & $60 \sim 75$ & $<30$ & $1.04 \sim 1.10$ & $32 \sim 50$ \\
\hline
\end{tabular}

\subsection{Plastic Concrete}

Plastic concrete is used to fill the panels of the cutoff wall. High deformability and plasticity are among the reasons to refer to this concrete as "plastic". The main factor to produce such qualities is bentonite powder. The compressive strength of the components of plastic concrete is much lower than the conventional structural concrete, while it has higher ductility and lower permeability. The plastic concrete mix proportion includes cement, bentonite, water, aggregates and, if necessary, admixtures. Table 2 demonstrates the plastic concrete properties of the cutoff wall of Karkheh Dam.

In general, there are two methods for determining the mechanical properties of plastic concrete: method of constant loading velocity and constant strain velocity. Since the loading rate increase at the construction site of the cutoff wall is very low, the constant strain rate method of ICOLD is acceptable. Ductility is an important issue in cutoff walls which is the linear gradient that connects origin coordinates of the strain-stress curve to the point of failure. It is necessary to consider the ductility of the wall to maintain compatibility between the foundation and cutoff wall and also to prevent failure of the dam under seismic or hydrodynamic loads. The cutoff wall is exposed to deformations due to consolidation imposed by self-weight of the dam. The cutoff wall is also exposed to increased water load or rise and fall of water level in the dam reservoir. The cutoff wall must be able to resist the deformations and applied loads during the construction and operation of the dam without cracking. It would be best when all the mechanical properties of plastic concrete, excluding permeability, are very similar to the foundation materials. However, in the Karkheh Dam project, this similarity was not observed due to wide variations of foundation properties. The International Commission on Large Dams (ICOLD) recommends that plastic concrete with a ductility factor of 4 to 5 times more than the surrounding soil is suitable for the cutoff wall. On the other hand, Young's modulus plays a very important role in the ductility of plastic concrete. The factors that affect Young's modulus are a function of the factors that affect the strength of
Table 2: Plastic concrete properties of the cutoff wall.

\begin{tabular}{ll}
\hline $3 \sim 7 \mathrm{MPa}$ & Compressive Strength \\
\hline $1 \times 10^{-8} \mathrm{~m} / \mathrm{s}$ & Permeability \\
$500 \sim 1000 \mathrm{MPa}$ & Young's Modulus \\
$170 \sim 220 \mathrm{~mm}$ & Slump \\
\hline
\end{tabular}

plastic concrete. These factors include bentonite (type and amount), water to cement ratio and aggregate grading. Based on ICOLD requirements, the Water-tocement ratio is equal to $\mathrm{c} / \mathrm{w}<0.5$. Increased strength and toughness of concrete are a consequence of increased w/c ratio, while the addition of bentonite ends up in reduced strength and increased ductility. Addition of aggregates to the mixture of cement and bentonite increases the toughness and strength of concrete. Also, increasing the concrete's age will increase Young's modulus, especially in high strength concretes. Fig. 4 highlights two different mix proportions of plastic concrete of Karkheh Dam (40 $\mathrm{kg}$ bentonite and $150 \mathrm{~kg}$ cement per cubic meter) with different aggregate dimensions and different loading rates. Fig. 7(a) shows that the plastic concrete with fine aggregates of $0 \sim 10 \mathrm{~mm}$ has lower values of ultimate stress, Young's modulus, and ductility in which the loading rate remained constant. Fig. 7 (b) shows that the compressive strength, and consequently, the Young's modulus (curve slope) increase due to reduced loading speed. Moreover, failure occurs in lower strains at higher loading speeds. Due to the low speed of loading during the construction of cutoff walls, the plastic concrete demonstrates higher plasticity compared to those of testing specimens in labs.

The Young's modulus is calculated with this formula:

$$
\mathrm{E}=\frac{\sigma_{2}-\sigma_{1}}{\varepsilon_{2}-0.00005}
$$

$\sigma_{2}=$ equivalent stress to $40 \%$ of maximum load capacity

$\sigma_{1}=$ equivalent stress to the strain of 0.00005

$$
\varepsilon_{2}=\text { equivalent strain to } \sigma_{2}
$$

Moreover, the stiffness and strength features of the plastic concrete in cutoff walls are designed in conformity with 


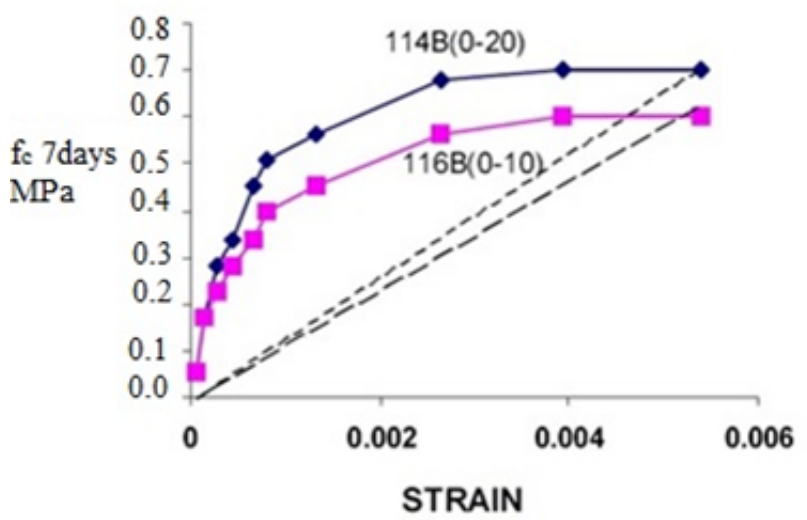

(a)

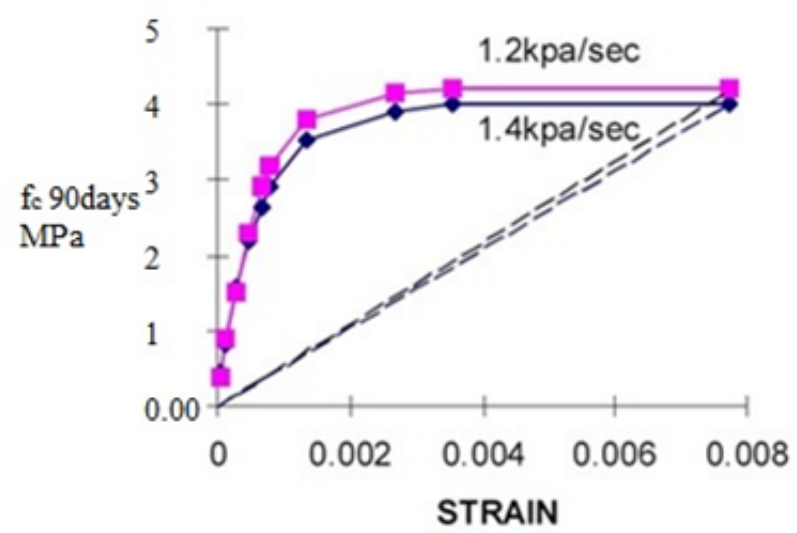

(b)

Figure 7: Maximum compressive strength variation and Young's modulus in plastic concrete, with different aggregate size (a) with different loading rates $(b)$.

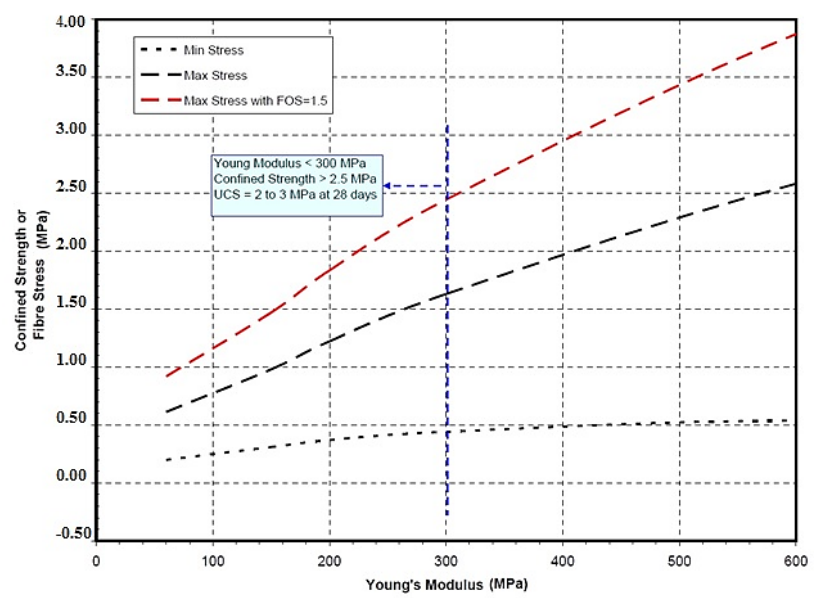

Figure 8: Plastic concrete mix strength and modulus design chart.

Table 3: Mix proportion design of a cubic meter of plastic concrete of the Karkheh Dam cutoff wall.

\begin{tabular}{ll}
\hline$f_{c-28}^{\prime}$ days MPa & 4.02 \\
$f_{c-7}^{\prime}$ days Mpa & 2.30 \\
Slump mm & $180 \sim 190$ \\
sand $0 \sim 5 \mathrm{~kg}$ & 780 \\
gravel $0 \sim 9.5 \mathrm{~kg}$ & 294 \\
gravel $9.5 \sim 19 \mathrm{~kg}$ & 555 \\
$\frac{w}{c}$ & 1.425 \\
Bentonite kg & 25 \\
cement kg & 200 \\
\hline
\end{tabular}

2-dimensional static and dynamic finite element software such as FEADAM [22] and [23] computer programs, respectively. The combined dynamic and static stress encloses (i.e., minimum and maximum fiber stresses) induced in the cutoff wall during an earthquake with a full reservoir were calculated as a variable of stiffness of the cutoff wall, Fig. 8. $^{[2]}$ As expected, a stiffer cutoff wall absorbs more stresses, and therefore, requires plastic concrete mix having higher strengths. The stiffness and stress of the cutoff wall shown in Fig 8 were calculated under the confinement of the soils. Therefore, the strength and stiffness design parameters are specified with effective confining soil stress of about $3 \mathrm{MPa}$. As shown in Figure 8, for Young's modulus less than $300 \mathrm{MPa}$, the confined strength required for a factor of safety of 1.5 is larger than $2.5 \mathrm{MPa}$. As the confined compressive strengths are typically 1.3 to 1.5 times higher than the corresponding unconfined compressive strength (UCS), a UCS of 2.0 to 3.0 MPa at 28 days is specified to control the strength.

Coarse and fine aggregates are the other components of plastic concrete that occupy almost $50 \%$ of its total volume. The amount of fine and coarse aggregates per volume is lower than normal concrete and is to a degree that prevents the aggregate interlock, and hence, improves the ductility of plastic concrete. Table 3 presents the mix proportion design of a cubic meter of plastic concrete of a cutoff wall. 


\section{Specific Construction Methods}

\subsection{Connection of Cutoff Wall with other Structures}

In some areas of the project, the cutoff wall is connected to other structures including culverts that divert water, spillways and Water Conveyance Tunnels (WCTs) of power plants. The different behavior of these structures compared to cutoff walls necessitates the formation of good connections. Since cutoff walls are relatively ductile with limited resistance as opposed to the previously mentioned rigid structures, the connection usually consists of the formation of a stress distribution area in the form of a connection key, and the layer between the cutoff wall and other structures is made of plastic and waterproofing materials. In the implementation of this seam, the use of bitumen as seam filler and low-level module lumber as separator and a hollow section for collecting excessive bitumen due to seepage of the outer structure to make proper compaction would be appropriate options. In addition, since adjacent parts of the cutoff wall could have differential settlements, construction of seams along with the insertion of rubber and copper sealing strips in the adjacent walls seems inevitable.

\subsection{Boiling Phenomenon}

During the construction of the panels of cutoff walls of Karkheh Dam, it was observed that a limited volume of water from the surface of the constructed panel was removed immediately after pouring concrete (Boiling Phenomenon). Typically, the slurry of water and cement and bentonite is removed from the surface of the concrete, and after a few hours, the color of the slurry becomes brighter and the solid particles inside the boiling mixture will gradually be reduced and eventually released from the panel surface in the form of smooth and clear water. Investigations proved that the boiling phenomenon generally occurred from dropping pipes with durations of at least 3 minutes to about 3 hours. A detailed study on the boiling phenomenon revealed that it was closely linked to the mix proportion design of plastic concrete, but the incorporation of appropriate construction methods could reduce the boiling amount. Hence, to avoid this phenomenon, the following measures are recommended (based on experiences concluded from the construction of Karkheh Dam's cut-off wall):
1. Increasing the amount of bentonite consumed in plastic concrete

2. Reducing the amount of water and cement

3. Decreasing the diameter of the aggregates (decreasing the diameter of the largest aggregates of stone materials)

4. Increasing the number of fine aggregates (aggregates passing through the No. $200[75 \mu \mathrm{m}]$ sieve)

5. Adding admixtures to concrete to increase shear strength and mortar specific gravity

\subsection{Flushing Phenomenon}

During the drilling of the cutoff wall of Karkheh Dam, the level of mud in mud tanks dropped significantly where the amount and volume of excavated material and consumed mud did not match, which could be an indication of flushing phenomenon. The main cause of the drop was the presence of open gravel areas in the wall of the cutoff wall. The flushing is a function of the head or a hydrostatic load of mud in the panel and the position of the pores and panel holes. In general, in order to avoid flushing, drilling muds with higher viscosity and density were considered.

\section{Seepage Analysis}

In this section, a numerical model using Seep-3D software was developed to evaluate the efficiency of the cut-off wall to decrease the seepage over the dam's foundation. To this end, the numerical results were validated by instrumentation statistics (from 17-years dam operation).

\subsection{Numerical Model}

The numerical model was developed in Seep-3D software where all seven materials used in the real dam project, including the dam's body and cut-off wall, were considered during simulation having the same material properties. These materials are introduced as clay core, shell (sand \& gravel), graded filter material, riprap (crushed rock), internal drain, conglomerate, mudstone, and cut-off wall. The model was simulated in 3-D in which the length from upstream to downstream was 1034 meter (x-direction), the depth from foundation to dam's crest was 164 meter (y-direction) and dam's cross-section along to the crest was 259 meter (z-direction). The model consisted of 


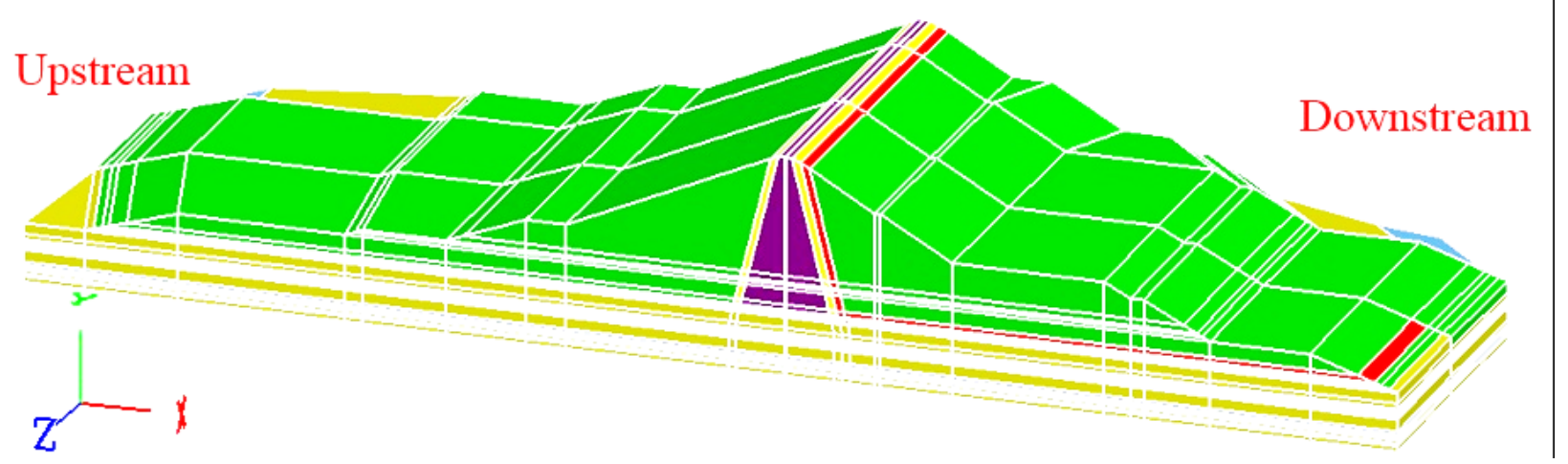

Figure 9: 3-D model of Karkheh Dam developed in Seep-3D software.
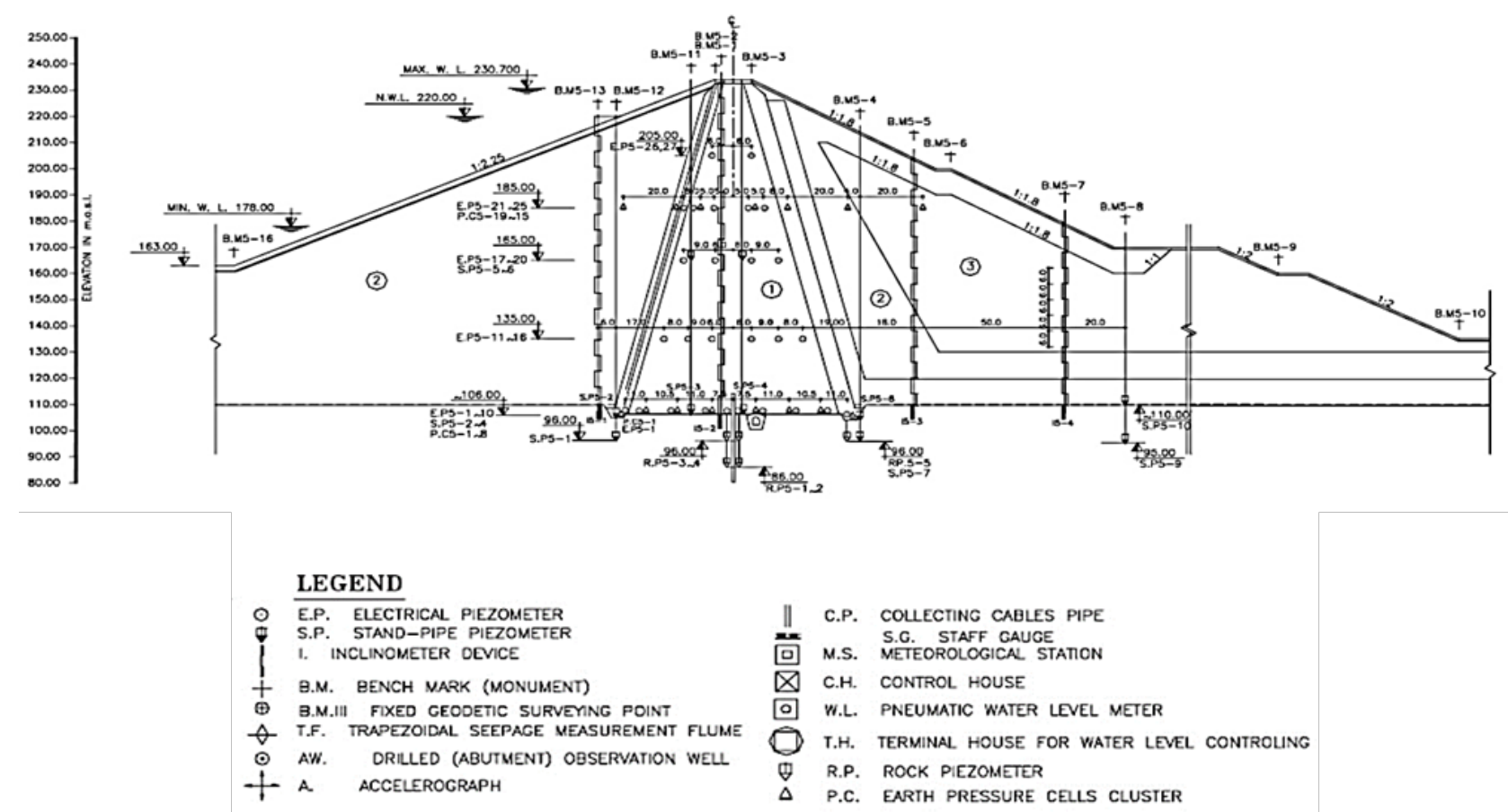

Figure 10: Typical instrumentation at one profile of Karkheh Dam "scale 1:500".

26,846 elements and water level in upstream and seepage in downstream were considered as the main boundary conditions. Fig. 9 shows the numerical model of the dam developed in Seep-3D software.

\subsection{The Instrumentation on Dam's Body and Foundation}

In order to study the effects of the cutoff wall on reducing the drainage and hydraulic gradient, it is necessary to install the precise instrumentations around the cutoff wall and clay core. These tools include:

i. Electrical piezometer

ii. Stand-Pipe piezometer

iii. Rock piezometer

iv. Earth pressure cells cluster

v. Inclinometer device

Fig 10 shows the location of these instrumentations in one of the profiles of Karkheh Dam. 


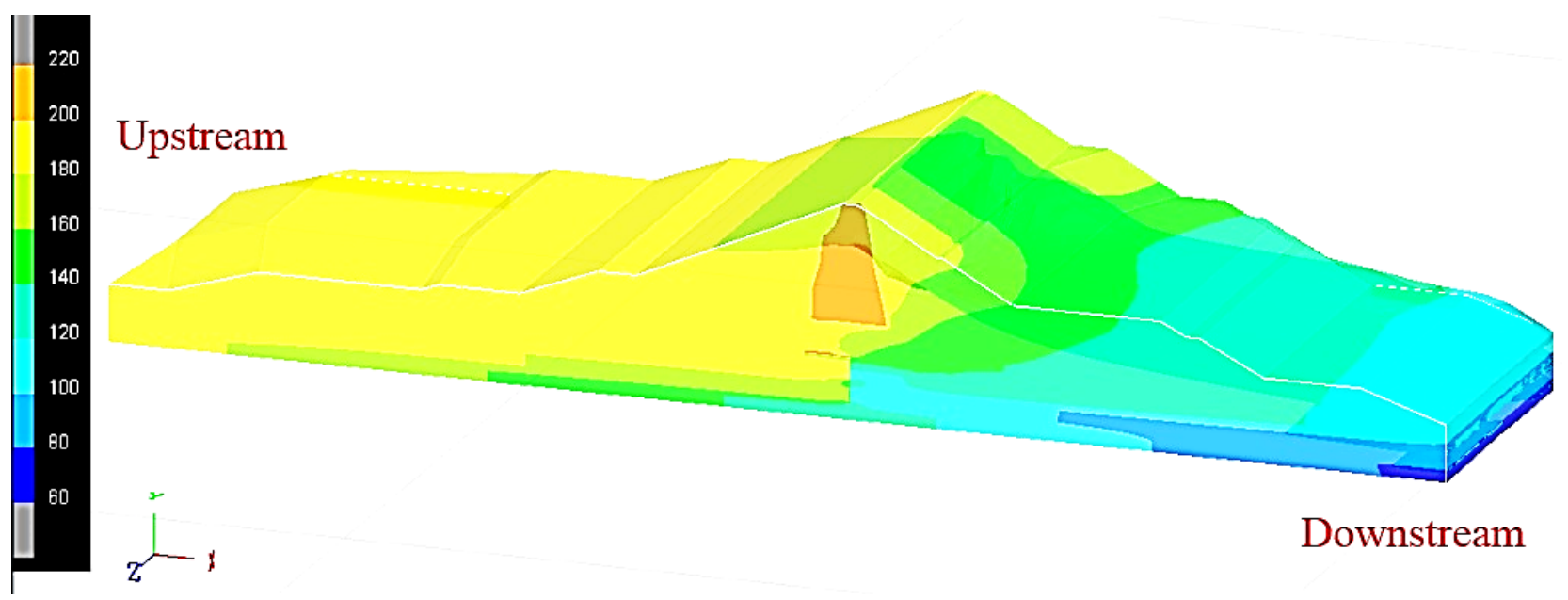

Figure 11: Three-dimensional contours and the piezometric pore-water surface under steady-state analysis.

\subsection{Analysis Results for Steady-State Flow Condition}

The rate of water flow and the distribution of water potentials in a one-dimensional soil column under steadystate conditions can be obtained by solving the Darcy or Buckingham-Darcy equation. The Darcy-Buckingham equation can be written as:

$$
q=-k(\theta) \frac{d H}{d x}
$$

Where $q$ is the flux density of water (or the volume of water flowing per unit time per unit cross-sectional area), $k(\theta)$ is the hydraulic conductivity of the soil at volumetric water content, $\theta, \mathrm{H}$ is the total water potential (or the sum of the gravitational and matric potentials), and $\mathrm{x}$ is the position coordinate in the direction of flow. The quantity $(-\mathrm{dH} / \mathrm{dx})$ is commonly called the driving force or hydraulic gradient.

Fig. 11 shows the pressure distribution and flow direction under steady-state analysis.

Table 4 comprises the pore-water pressure variation among the installed piezometers and numerical model developed in Seep 3-D along 3 different levels of the dam's body and foundation. To this end, instrumentation statistics resulted from 17-years dam's operation were taken into account.

The variation of pore-water pressure in different foundation's location resulted from installed piezometers and numerical model, developed in Seep 3-D, for 10 different water levels are shown in Figs. 12 and 13 respectively.

\subsection{Analysis Results for the Transient Flow Condition}

The flow of water in unsaturated soils may vary both spatially and temporally due to several factors. Timedependent changes in the boundary conditions (infiltration-evaporation) can significantly influence the flow mechanism. Such changes are accounted for by the theoretical models by considering these changes in terms of boundary conditions for the soil domain. Fig. 14 shows the pressure distribution and flow direction under transient flow analysis.

Table 5 comprises the pore-water pressure variation resulted from installed piezometers and numerical model for water level 156.87 over two different time periods.

The results of Table 5 for time interval $\mathrm{dt}=4800 \mathrm{~s}$ presented in the line graph are shown in Fig. 15. The graph indicates that there is a good agreement between instrumentation results and numerical simulation. In addition, taking into account the period of 38-days leads to better prediction of pour-water pressure considering instrumentation results.

\subsection{Performance of Complementary Cut-Off Walls}

Fig. 16 shows the variations in water levels in piezometers mounted around the spillway after complementary cut-off walls project over a 4-year period. Considering Fig. 16, it is evident that the piezometer installed in downstream of the cut-off wall, RP 10-5 DS, experienced a significant 







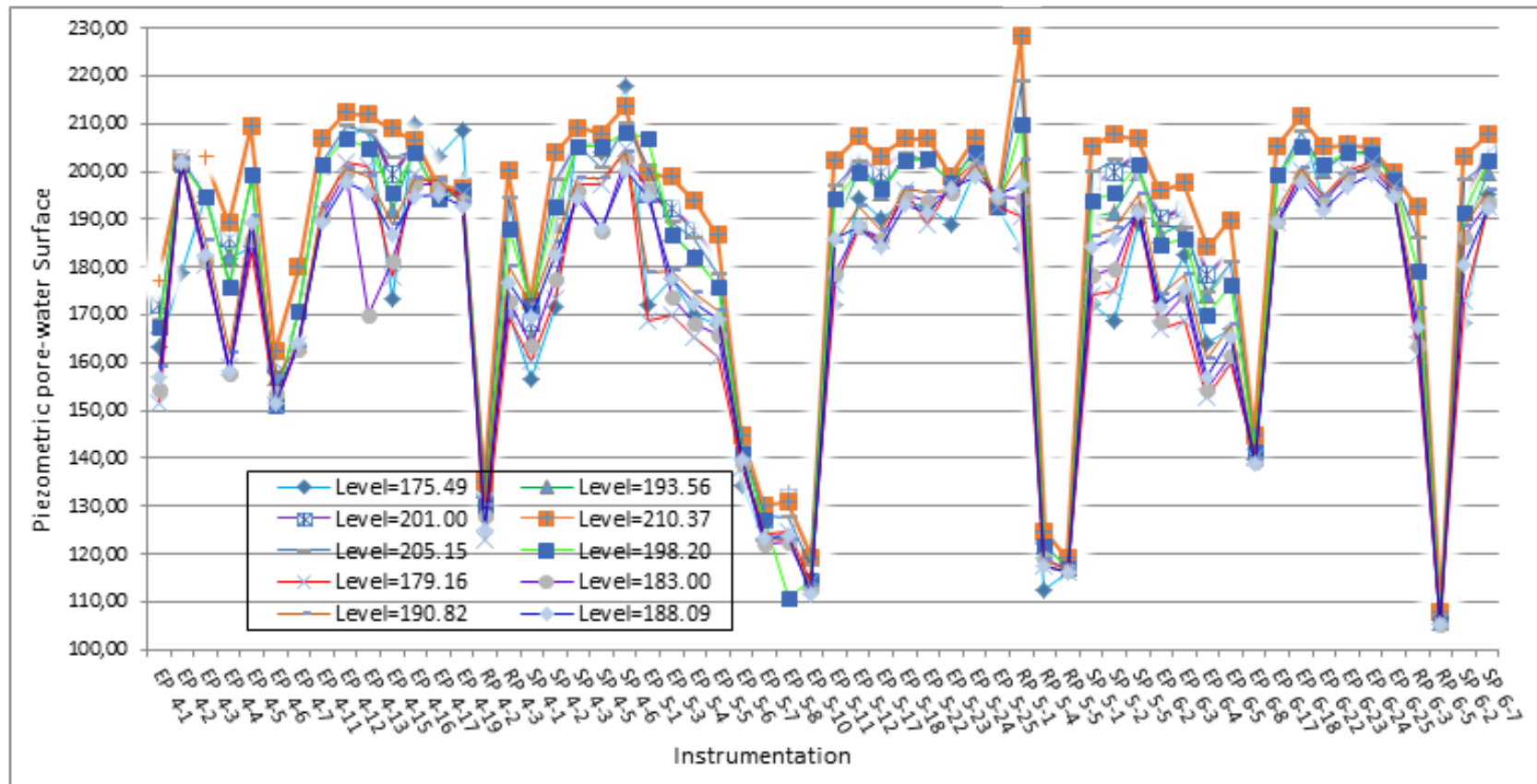

Figure 12: Variation of piezometric pore-water surface resulted from instrumentation.

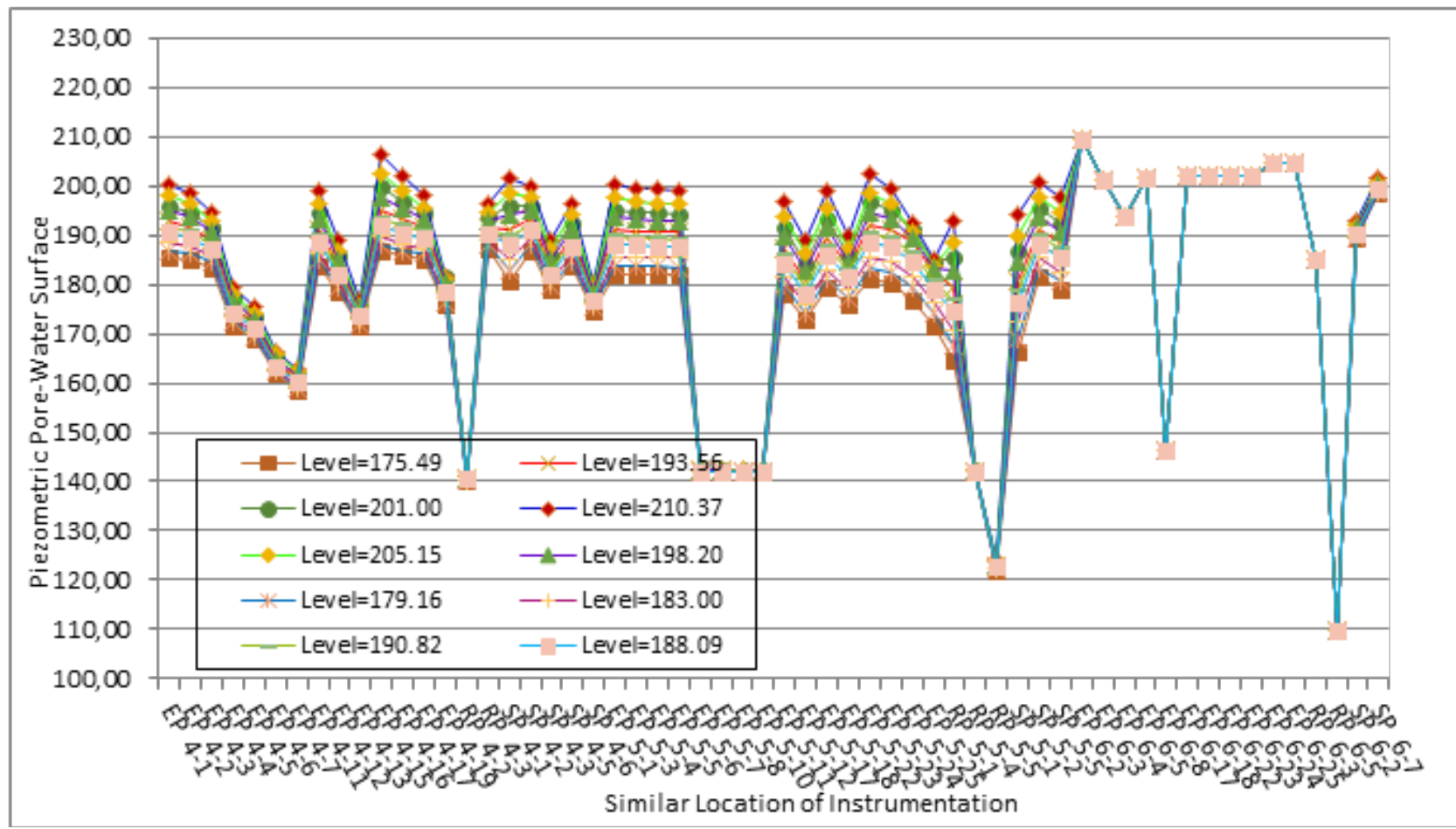

Figure 13: Variation of piezometric pore-water surface resulting from numerical simulation. 


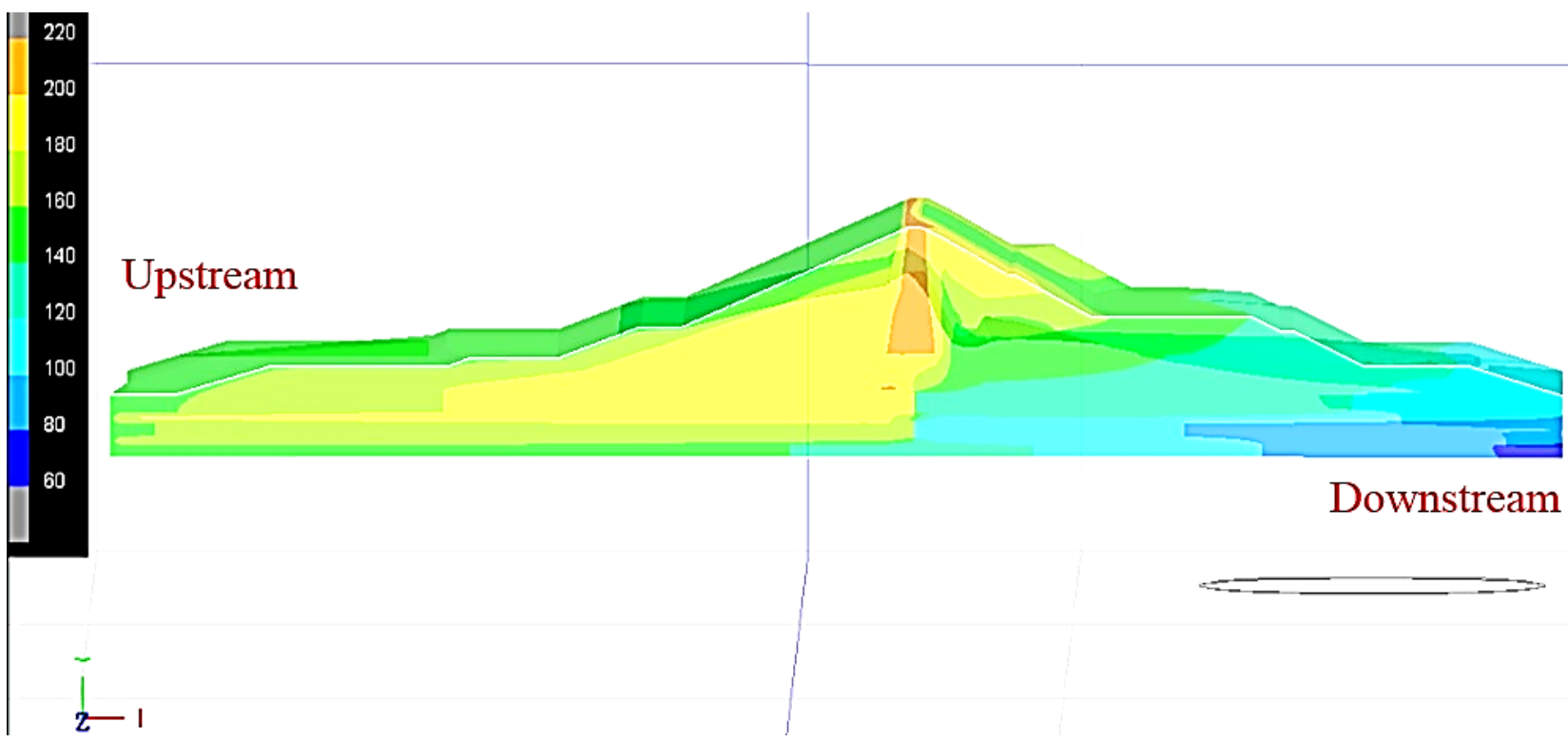

Figure 14: Pressure distribution and flow direction under transient analysis.

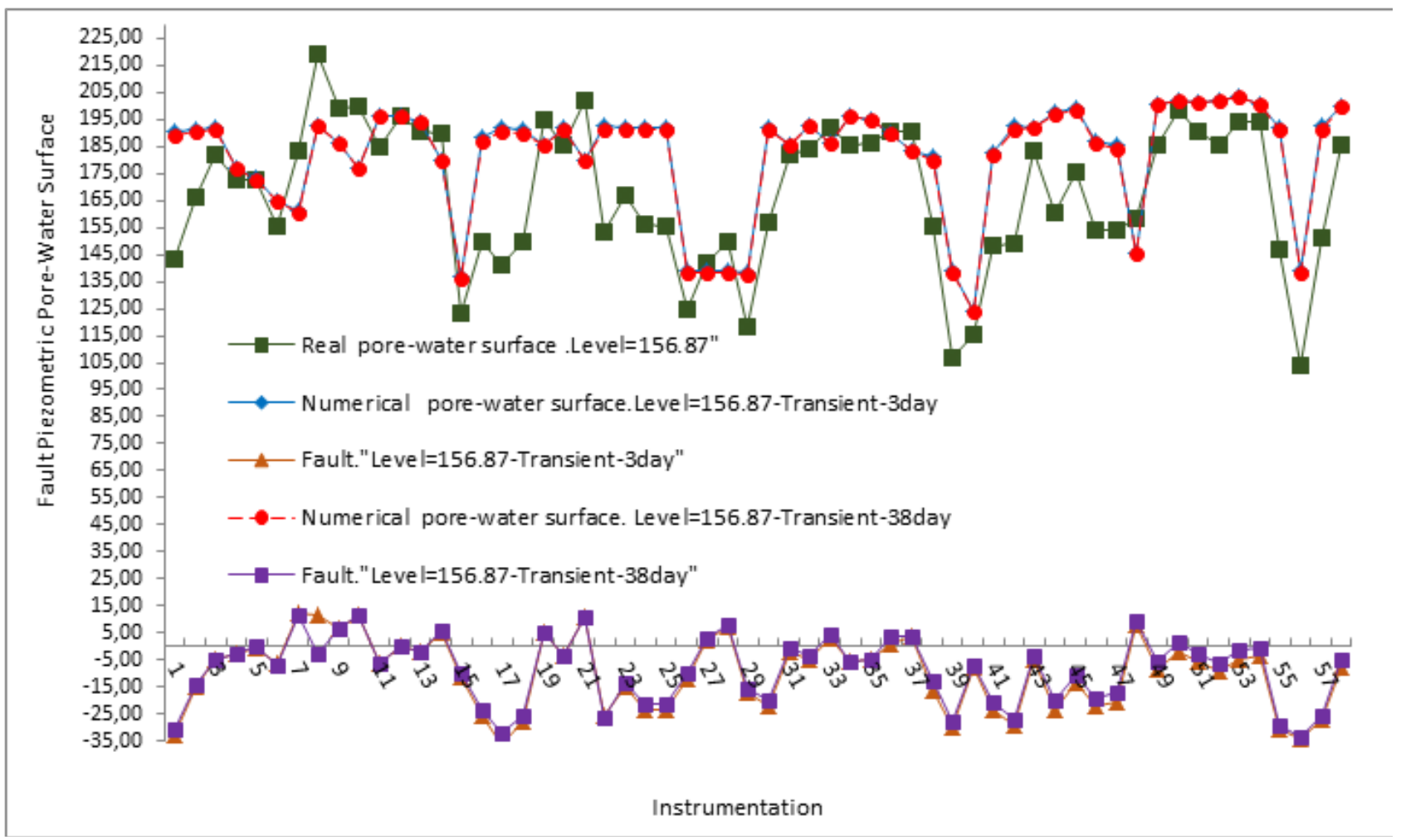

Figure 15: Comparison between numerical and piezometers pore-water pressure for time interval $\mathrm{dt}=4800 \mathrm{~s}$. 


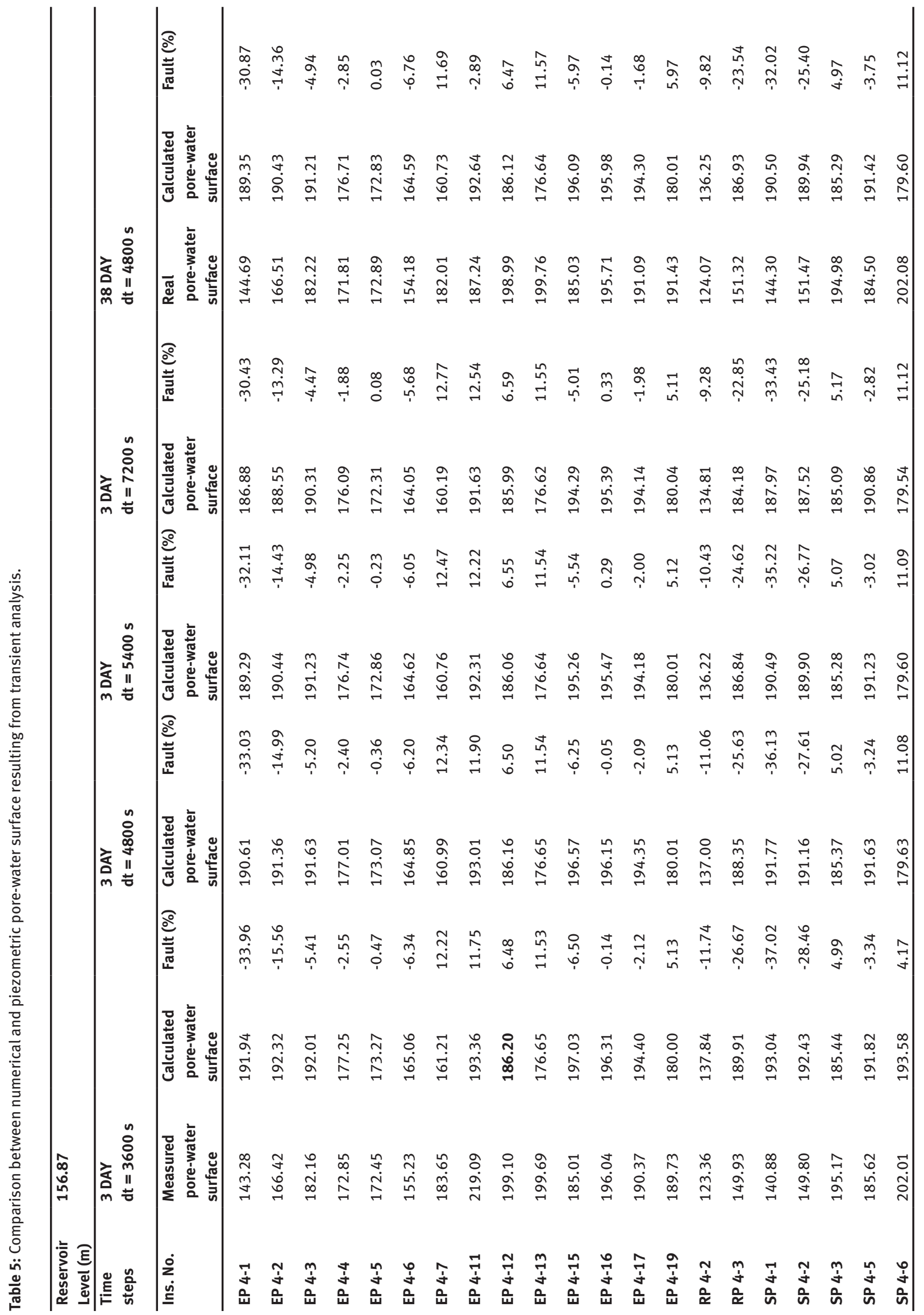




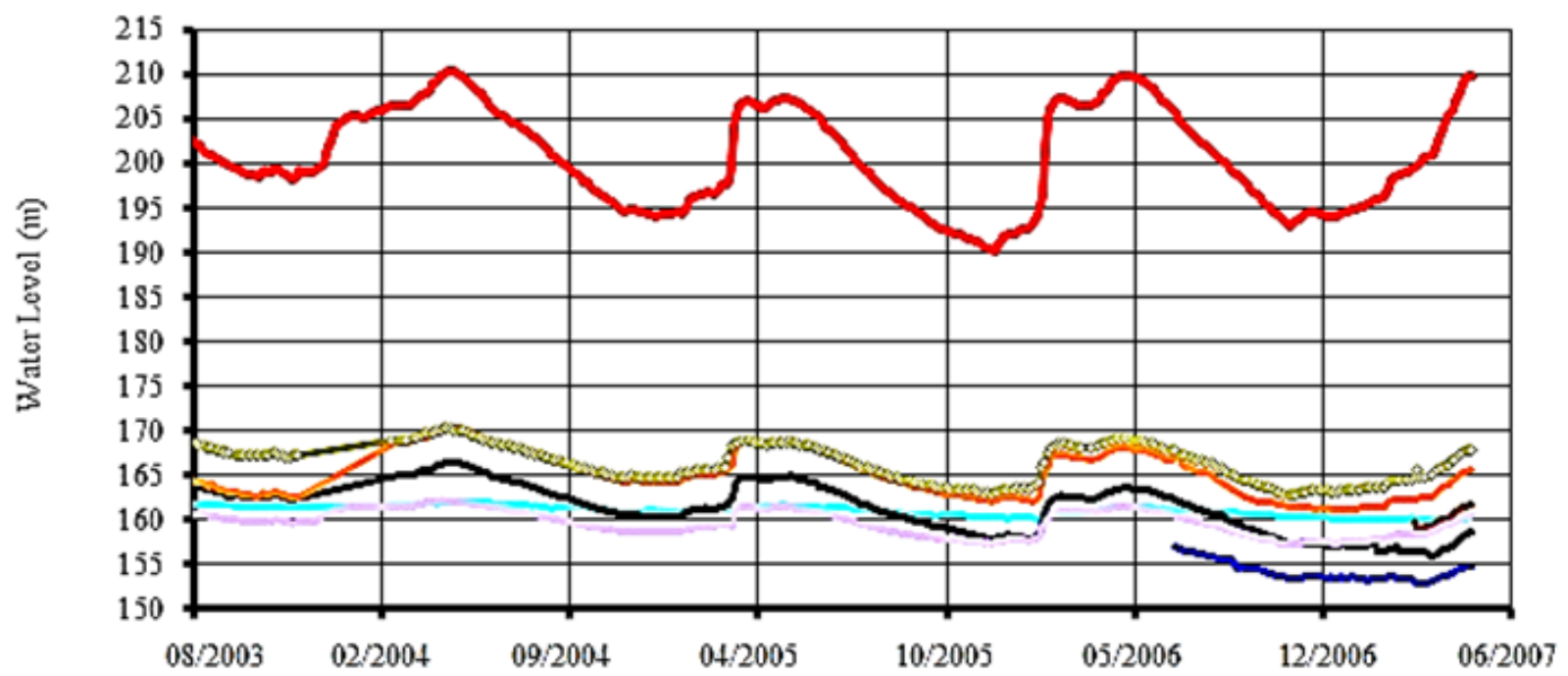

Date

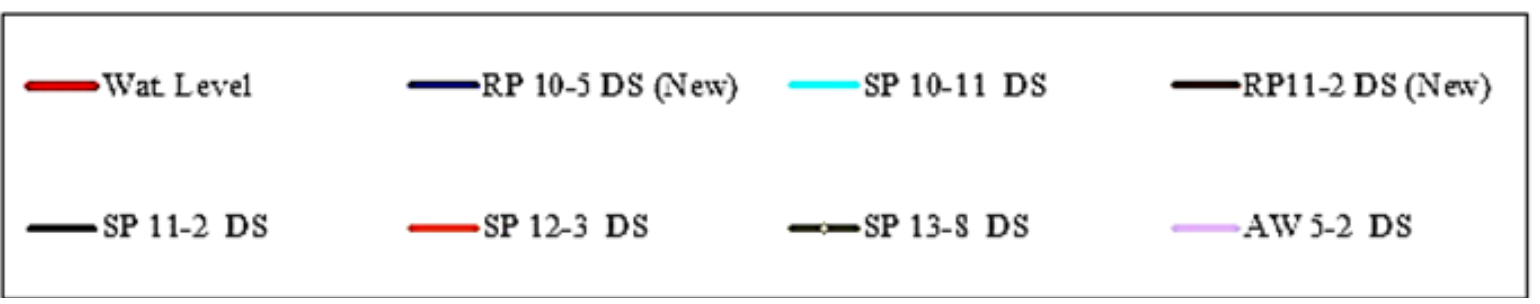

Figure 16: Variation in the reservoir water level and piezometers after complementary cut-off walls project.

decrease after the completion of the complementary cut-off wall in 2006.

In general, the main objective of construction of the cutoff wall of Karkheh Dam was to reduce the average hydraulic gradient in different layers to less than 0.07 . Implementation of the complementary cutoff wall reduced the hydraulic gradient to around 0.08 and reduces the water drainage by 3.1 cubic meters per second, which is almost acceptable. It is noteworthy to highlight that the seepage rate through drainage systems in the downstream of the dam includes filters and drainage blankets, drainage wells, and water pressure regulators.

\section{Conclusions}

This paper has examined the methods of construction and design of the Karkheh Dam cutoff wall. Materials used in plastic concrete of the wall were briefly investigated. The data obtained from precise instrumentations were used to study the effects of the cutoff wall on the reduction of seepage and hydraulic gradients. The results of this research are summarized as follows:
1. Increased coarse aggregates and reduced loading speeds led to increased compressive strength and Young's modulus of the plastic concrete of the cutoff wall.

2. In order to connect the cutoff wall to other structures such as spillways and Water Conveyance Tunnels (WCTs), incorporation of high ductility materials such as bentonite in the connection is recommended.

3. Boiling and flushing phenomena are connected with the mix proportion design of plastic concrete and the hydrostatic load of the mud in the panel, respectively. In order to avoid such phenomena, increasing the amount of bentonite used in plastic concrete and incorporation of drilling mud with high viscosity and high density is greatly recommended.

4. By using numerical simulation, it is possible to determine the pore-water surface in any section, since this is a critical point to estimate the demanded cut-off wall distance and depth in order to minimize the seepage.

5. The results of piezometers on the sides of the cutoff wall showed that the implementation of the cutoff wall with plastic concrete reduced the hydraulic gradient by 0.08 from 2.35 and the water leakage by $3.1 \mathrm{~m} / \mathrm{s}$ from $18.3 \mathrm{~m} / \mathrm{s}$, which is satisfactory. 


\section{References}

[1] Meneylyuk, A., et al., Innovative technology of horizontal protective shield arrangement using injection. E-GFOS, 2017. 8(15): p. 36-49.

[2] Yan, L., D. Trapp, and A. Sy, Construction of a Plastic Concrete Seepage Cutoff Wall for the New Coquitlam Dam. 2008.

[3] MacGregor, P., et al., Geotechnical engineering of dams. 2014: CRC press.

[4] Hong, E.-S., et al., Characteristics of failure surfaces induced by embankments on soft ground. Geomechanics and Engineering, 2014. 6(1): p. 17-31.

[5] Abbaslou, H., A.R. Ghanizadeh, and A.T. Amlashi, The compatibility of bentonite/sepiolite plastic concrete cut-off wall material. Construction and Building Materials, 2016. 124: p. 1165-1173.

[6] Ghanizadeh, A.R., et al., Modeling of bentonite/sepiolite plastic concrete compressive strength using artificial neural network and support vector machine. Frontiers of Structural and Civil Engineering, 2019. 13(1): p. 215-239.

[7] Zhang1a, H., et al., Application of a modified structural clay model considering anisotropy to embankment behavior. GEOMECHANICS AND ENGINEERING, 2017. 13(1): p. 79-97.

[8] Zhang, G., et al., Linear regression analysis for factors influencing displacement of high-filled embankment slopes. Geomechanics and Engineering, 2015. 8(4): p. 511-521.

[9] Bond, A.J., et al. Eurocode 7: geotechnical design worked examples. in Workshop "Eurocode". 2013.

[10] di Cervia, A.L.R., Slurry trench method and apparatus for constructing underground walls. 1987, Google Patents.

[11] Evans, J., et al. Soil-bentonite slurry trench cutoff wall lateral deformations, consolidation, stress transfer and hydraulic conductivity. in Proceedings of the 2nd symposium on coupled phenomena in environmental geotechnics (CPEG2), Leeds, UK. 2017.

[12] Li, Y.-C., et al., Stresses in soil-bentonite slurry trench cutoff walls. Géotechnique, 2015. 65(10): p. 843-850.

[13] Kato, S., Method and apparatus for forming underground construction in situ. 1970, Google Patents.

[14] Dias, D. and J. Grippon, Numerical modelling of a pilesupported embankment using variable inertia piles. Structural Engineering and Mechanics, 2017. 61(2): p. 245-253.

[15] Anderson, T.C., $m /$ sant piles support access shafts for tunnel crossing in difficult geologic conditions, in GeoSupport 2004: Drilled Shafts, Micropiling, Deep Mixing, Remedial Methods, and Specialty Foundation Systems. 2004. p. 299-308.

[16] Pakbaz, M., A. Dardaei, and J. Salahshoor, Evaluation of performance of plastic concrete cutoff wall in Karkheh Dam using 3-D seepage analysis and actual measurement. Journal of Applied Sciences, 2009. 9(4): p. 724-730.

[17] Heidarzadeh, M., et al., Construction and performance of the Karkheh dam complementary cut-off wall: an innovative engineering solution. International Journal of Civil Engineering, 2018: p. 1-11.

[18] Wen, L., et al., A statistical analysis on concrete cut-off wall behaviour. Proceedings of the Institution of Civil EngineersGeotechnical Engineering, 2018. 171(2): p. 160-173.
[19] Xiong, H., et al., Stress deformation analysis of plastic concrete cutoff wall for the first stage cofferdam of Shawan hydropower station [J]. Journal of Hydroelectric engineering, 2010. 2.

[20] Hinchberger, S., J. Weck, and T. Newson, Mechanical and hydraulic characterization of plastic concrete for seepage cut-off walls. Canadian Geotechnical Journal, 2010. 47(4): p. 461-471.

[21] Design Standards No. 13, Embankment Dams B.o.R. U.S. Department of the Interior, Editor. 2014.

[22] Duncan, J., et al., A computer programfor finite element analysis of dams. Research Repor No. 1984, SV/GT/84 03.

[23] FLUSHPLUS, A., computer program for approximate 3-D analysis of soil-structure interaction problems. An enhanced PC version of the original FLUSH program published in, 1975. 